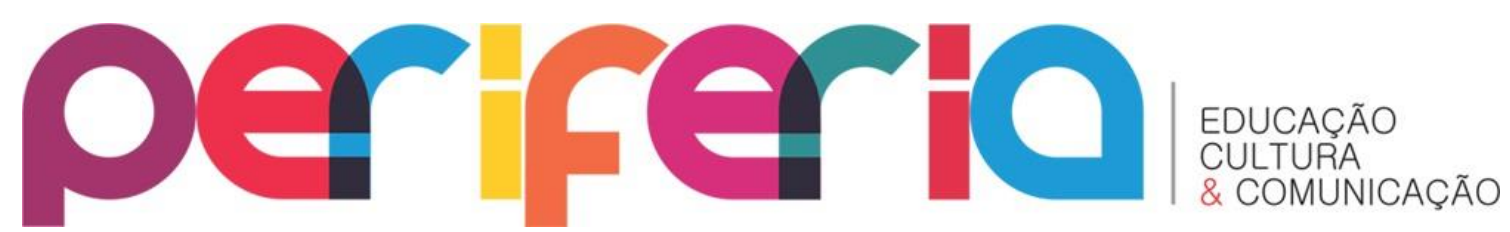

\title{
CANDOMBLÉ E AS DUAS DIÁSPORAS DO POVO NEGRO: O PAÍS MÍTICO E A INVASÃO DA TOLERÂNCIA
}

\section{CANDOMBLÉ AND THE TWO DIASPORAS OF THE BLACK PEOPLE: THE MYTHICAL COUNTRY AND THE INVASION OF TOLERANCE}

Alisson Araujo de Almeida ${ }^{1}$

\begin{abstract}
Resumo : Este artigo é um desdobramento da revisão bibliográfica realizada para a pesquisa de doutorado Les jeux de Masque au sein du Candomblé, Dramaturgia de la Fête dans l'Espace. O olhar antropológico ofereceu uma atenção maior ao processo de reconstrução da alteridade negra na diáspora brasileira. Através das leituras feitas o Candomblé passou a ser compreendido como uma unidade nas diferenças, onde o acesso aos ancestrais permite a expressão de alteridades. Contudo, as reflexões aqui lançadas pretendem verificar as diversas visões que têm gerado uma evasão no Candomblé e um aumento da intolerância. Assim, este artigo é o embrião de uma futura pesquisa que irá investigar a potência criativa do Candomblé assim como suas contradições.
\end{abstract}

Palavras Chaves: Candomblé - diaspora - mestiçagem - intolerância - alteridades

Abstract: This article is a further development of the bibliographic revision carried out for the doctoral research Les jeux de Masque au sein du Candomblé, Dramaturgia de la Fête dans l'Espace, through which the Candomble started to be understood as a unity in the difference, where access to the ancestors allows for the expression of alterities. However, the reflections outlined here intend to verify many different visions that have been generating an evasion within Candomblé, and an increase of intolerance. Hence, this article is an embryo for a future research that aims to investigate the creative potency of Candomblé as well as its contradictions.

Keywords: Candomblé - diaspora - miscegenation - intolerance - alterity.

Este artigo é uma reflexão sobre o movimento cultural decorrente da capacidade dos povos afro-brasileiros de resistir à condição de escravos na qual chegaram no Brasil.

\footnotetext{
${ }^{1}$ Diretor, dramaturgo, professor de teatro e adepto do Candomblé. Doutorando em Esthétique, sciences et technologies des arts, spécialité théâtre et danse, na linha de Ethnoscenologie, pela Universidade Paris 8 - Vincennes - Saint-Denis. Bolsista de doutorado pleno no exterior financiado pela Coordenação de Aperfeiçoamento de Pessoal de Nível Superior - CAPES
} 


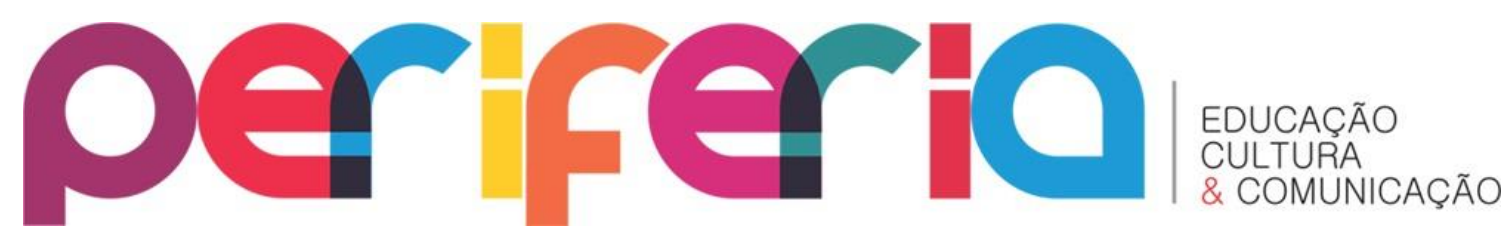

E por consequência, um contrastar à hegemonia do pensamento ocidental que impôs a eles uma anulação de suas subjetividades.

Desta forma, as estratégias de resistência produziram um conjunto de normas estruturais de uma sociedade que perpassa a ordem religiosa e indicam condutas civis, formando assim uma segunda sociedade dentro da grande sociedade brasileira.

Podemos pensar então, os Terreiros de Candomblé, como quilombos urbanos, onde a religiosidade possibilita a construção de uma cosmovisão de organização social, que permite ao indivíduo a expressão de sua subjetividade numa ordem lúdica.

Diáspora refere-se a dispersão de um povo por motivos políticos ou religiosos. Normalmente, usa-se esse termo para definir o exílio sobretudo dos povos judeus no exílio babilônico² ${ }^{2}$

Ao cruzar o oceano Atlântico rumo ao desconhecido sob a condição de escravos, os negros africanos provenientes de distintas etnias, não faziam idéia que estavam se dirigindo na ocupação de um país continental.

Um requisito para atravessar o oceano era que esses negros passassem por um batismo e tornassem "cristãos". Isso evitaria qualquer responsabilidade e por consequência a ira divina para os senhores que realizavam o translado. A conversão na nova religião, impunha já na partida a transformação cultural do sujeito africano. Dessa forma,, ele estava impossibilitado de trazer objetos, instrumentos, máscaras, vestimentas, ou seja, qualquer aparato que o permitisse a expressão de sua subjetividade, de sua alteridades. ${ }^{3}$

Logo, essa diáspora africana para o Brasil que durou cerca de 300 anos, trata-se de um processo diferente daquele sofrido pelo povo judeu. Embora esses dois povos

\footnotetext{
${ }^{2}$ Utilizamos do dicionário online devido o autor se encontrar no processo final de doutoramento, impossibilitado assim de acessar ao dicionário impresso. http://michaelis.uol.com.br/modernoportugues/busca/portugues-brasileiro/Diaspora

${ }^{3}$ Dado encontrado no filme“Devoção" Documentário sobre o mito do sincretismo no Brasil - possível de ver no youtube no endereço https://www.youtube.com/watch?v=GzNA9JP45G8, a partir do minuto 14:44 à historiadora da UFF, Mariza Soares e a professora da UFRRJ, Beatriz Catão falam sobre esse fato.
} 


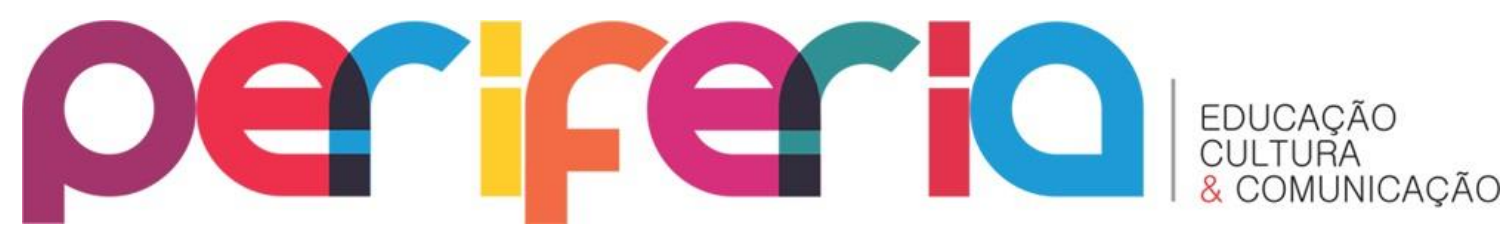

foram obrigados a migrar, os judeus puderam transportar os aparatos materiais necessários para à continuidade de sua expressão subjetiva. Outro fator importante à acrescentar é que na diáspora do povo judeu, esse se manteve unido como uma mesma “tribo". Já o ocorrido com os africanos foi diferente, além de serem impossibilitados de conduzir seus aparatos materiais, houve uma mistura de distintas tribos, algumas inclusive rivais. Logo à reconstrução de alteridade na diáspora africana para o Brasil ocorre através de fragmentos de memórias nessa mistura de tribos.

Assim, a diáspora negra para Brasil passa por dois processos de dispersão, inicialmente é o translado para o novo país e em seguida a estratégia de misturar povos de etnias diferentes para evitar revoltas contra os senhores brancos. Assim não apenas obriga-se a migração para outras terras como acrescenta a esse fato a dispersão desse povo por todo território ocupado.

Essa estratégia de misturar as etnias, ao invés de produzir uma hecatombe e por consequência, uma ampliação da dispersão, ao contrário causou uma aproximação, uma coesão e uma (re)construção de laços familiares.

Importante lembrar que, a percepção que temos hoje de nacionalidade, de país e de identidade é algo que fora formado justamente no período na expansão marítima. A própria Europa era formada por distintos reinos, cada qual seria um país, as semelhanças entre eles eram estabelecidas pelas inúmeras trocas e acordos, sobretudo matrimoniais que em seguida daria a união no que hoje chamamos nação.

$\mathrm{Na}$ África essa realidade não era diferente. Uma extensão espacial abrigava distintos grupos humanos que compartlilhavam entre si elementos em comuns, dentre eles a língua, ou melhor, uma maneira de se comunicar que partilhavam o mesmo troco linguístico. Por exemplo os Bantos.

São cerca de 500 línguas aparentadas [...] línguas essas faladas por povos negros que vivem na Africa sub-saariana, e que teriam um tronco linguistico comum, o povo-banto. Portanto, quando falamos em banto estamos nos referindo a povos e etnias cujas línguas têm um tronco comum e não a povos com traços raciais próximos. (ADOLFO, 2010, p 5) 


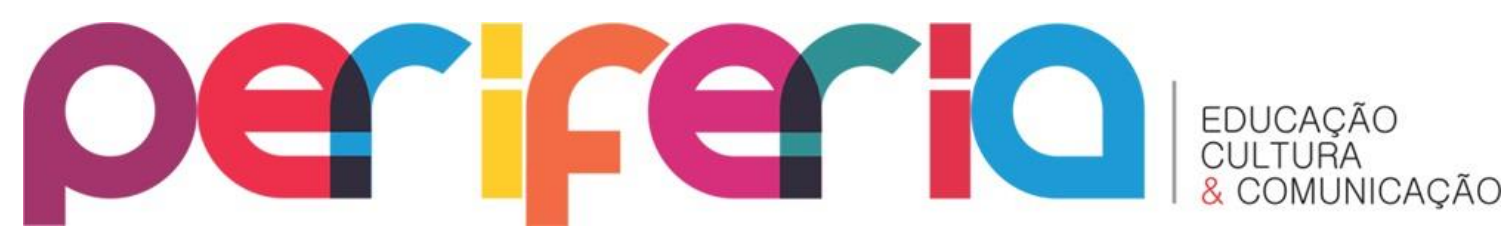

Sublinho que essas formas de falar não estavam submetidas a uma gramática, como nos estudos linguísticos atualmente nos impõem. O objetivo da língua era de se comunicar. Assim como ocorre ainda hoje, mesmo em algumas línguas européias, onde as pessoas se comunicam e se compreendem, contudo cada um guarda o seu vocabulário e sua construção de frases, mas mesmo assim conseguem compreender o sentido das orações, gerando uma comunicação eficaz entre povos que falam línguas diferentes, mas por possuirem o mesmo tronco linguistico se fazem comunicar.

Apesar das diferenças, existe uma semelhança nas manifestações culturais que hoje em dia os intelectuais africanos começam a definir como Africanidade ${ }^{4}$. Esse conceito esta diretamente vinculado a ligação estreita desses povos com o culto aos ancestrais. E justamente é a ancestralidade que permitirá um recriar de elementos culturais (ritualísticos e de lazeres), no novo mundo como meio de resistência a cultura imposta pelos portugueses.

\section{A rede de ancestrais}

O pensamento africano parte do pressuposto que o ser humano não nasce pronto, e são os rituais de passagem que permitirão o desenvolvimento dessa alma. Logo, ao se verem no território hostil da colônia portuguesa, impedidos da livre expressão de sua alteridade. Os povos africanos se agruparam em reconstruções de rituais, que permitissem esse desenvolvimento de suas alteridades.

Como nas senzalas esses povos estavam misturados em tribos distintas de africanos e por vezes mesmo de índios brasileiros, eles passaram a se organizar pela ordem de ancestralidade. Quer dizer que o mais velho iria cuidar do mais novo, criando assim parentescos familiares de ordem espiritual.

\footnotetext{
${ }^{4}$ Aprendi esse conceito à partir da mesa redonda I Encontro de Subjetividade e Cultura Afro-brasileira. Ancestralidade, cultura e práticas de cuidar nos terreiros. Conferência que pode ser vista no endereço https://www.youtube.com/watch?v=OWVfQkUsRHs\&list=LLm3K7Iyo0sJPfyaaLV7tMtQ\&index=12, à partir do minuto 29:06
} 


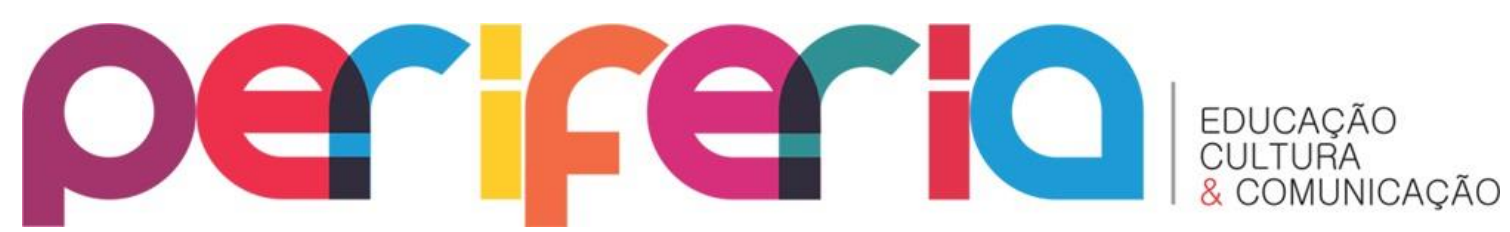

Como já mencionado os povos pertenciam a tribos, reinos diferentes. Logo os ritos de passagem não seriam "puros", pois o mais velho iria iniciar e desenvolver o mais novo nos cultos aos ancestrais, a partir de suas própria ancestralidade. Ou seja, se a mãe era de Mikaia ${ }^{5}$ e iria iniciar alguém de Nsumbo, tribos diferentes, ela iria fazer à partir dos ritos executados em sua própria ancestralidade.

Contudo, devemos lembrar que se tratam de ritos vivos, da ancestralidade que se comunica durante todo o processo de iniciação. Logo, foram elaborados diálogos entre essas comunidades diferentes, com permissão das próprias divindades que aceitavam o novo procedimento como parte necessária ao desenvolvimento do laço com o neófito.

Vale ressaltar ainda que, os africanos não eram regidos pela escrita e por consequência por livros, sendo assim, sua prática era pautada na oralidade, ou seja, o registro dos rituais estavam conservados na memória corporal. Esses fragmentos de memórias corporais foram se unindo, formando assim um mosaico de ritos e fundamentos, que conduziram e conduzem as iniciações e desenvolvimentos das práticas aos ancestrais no qual chamamos de Candomblé.

Mesmo pertencente a tribo que cultuava Nsumbo ao ser iniciado por uma mais velha de Mikaia, o neófito herda também a ancestralidade de sua iniciadora. E depois de passar pelos ritos necessários e ganhar o direito de iniciar outras pessoas, por exemplo, se ele iniciar alguém de Matamba, essa ira receber a ancestralidade de Nsumbo e de Mikaia.

Por consequência, trata-se de uma complexa rede de ancestrais que indicaram caminhos necessários para estabelecer os fundamentos essenciais de um noviço, dentro desta mestiçagem de cultos e ritos recriados no Brasil.

Essa rede de ancestralidade é ainda mais complexa. Pois ela diz respeito não só as tribos distintas, que ocupavam um mesmo território, como engloba ainda ancestralidades de etnias distintas a exemplo os Yorubás, os Ijexás, os Cambindas.

\footnotetext{
5 A escolha pelo uso dos nomes das divindades como nomeamos no Candomblé Angola, ocorre por ser essa à tradição que estou inserido. E igualmente pede um movimento do imaginário do Candomblé, que embora sejam energias semelhantes, essas podem ser nomeadas de outras maneiras.
} 


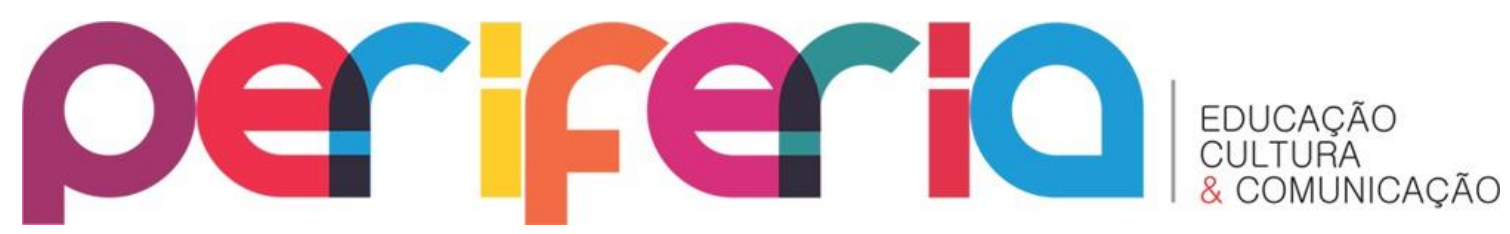

O antropólogo francês François Laplantine e o antropólogo canadense Alexis Nous, falam da potência criativa e subversiva da mestiçagem. Através de viagens e encontros, a transição de si para o outro não se apresenta como uma problemática de perda de identidade, mas como um alargamento de saberes. Onde a originalidade não está em criar uma identidade uno mas criar uma pluralidade. (1997, p. 27).

Um espaço de diálogo mas também de confronto, onde a contaminação, a somatória de 1+1 resulta em 3. Diferente da noção de sincretismo, onde há uma subjugação de um elemento em relação ao outro, onde a multiplicidade é diminuída na unidade. A mestiçagem é a coabitação dos diversos elementos presentes no corpo do terceiro elemento que produz sua própria individualidade à partir do múltiplo e não do uno. Esse terceiro elemento é justamente a parcela originaria servindo como referecia as ancestralidades.

\footnotetext{
A especificidade de uma cultura ou de um indivíduo, vem das combinações infinitas que podem ser produzidas - fora da gente, mas também dentro da gente, existem multiplicidades - , agenciamentos de termos heterogêneos, distintos, diferentes, em resumo a reformulação de varias heranças. (LAPLANTINE e NOUS 1997. p, 76) ${ }^{6}$
}

Essa potência de agenciamento do diferente, ramifica o Candomblé numa árvore que cria um acesso ao ancestral. Essa árvore com distintas raízes que se cruzam, dando uma personificação de caminho dentro do território que está plantada. Não é a toa que o Candomblé faz tantas referências a horticultura.

Dentro da diáspora negra o Candomblé criou mais do que uma identidade. Essa prática criou sobretudo um TERREIRO, onde a multiplicidade de expressão da alteridade, do indivíduo se tornou possível. Vejo como um grande país mítico, onde cada Nação é uma forma de acentuar um linguajar.

.6 -6 Tradução livre do francês realizada pelo autor. 


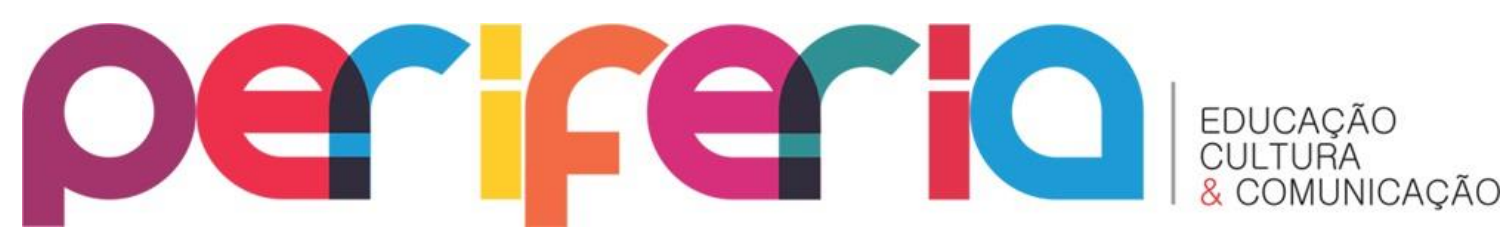

Para além da Nação, existem ainda outras maneiras de reconhecimentos dentro do Candomblé. Reconhecimentos de alteridades que perpassam o pensar ocidental de identidade. A pessoa não tem apenas a identidade de ser de Nação Angola, Nação Ketu, Nação Jeje, Nação Xamba, Nação Efon, Nação Ijexá. Existe ainda o pertencimento a uma nação metafísica e elementar. Um parentesco ligado a divindade ou ao elemento que essa pertence.

Quando alguém argumenta que, o que chamamos hoje de qualidade era divindade diferenciada na África. Certamente era, mas no Brasil passou a ser tida como qualidade, porque se misturou maneiras de cultivar. Assim quem era de Oxum, foi cuidada com fundamentos de Kissimbi, de Dandalunda, de Yalode, de Kare, de Ponda, etc, formando assim uma maneira afro-brasileira de cultivar as divindades das águas ligadas ao útero e o amor. E o mesmo ocorreu com as outras divindades.

Para exemplificar a mestissagem presente no Candomblé sirvo-me da filosofia do povo Banto, lembrando que esses foram os primeiros povos trazidos ao Brasil na diáspora africana. Assim, para os Bantos e grande parte do mundo negro africano, os indivíduos são parentes seja por um laço direto de família, seja por meio de um pertencimento clanique comum, seja ainda em virtude de casamentos. (KOLEAS 2007, p.25).

Portanto, o que o Candomblé realizou foi o reencontro de clans míticos em laços familiares, que perpassam o parentesco familiar criado por um praticante de uma mesma casa-raiz. Mesmo que sejam de nações diferentes, esses povos se encontram nas alteridades de seus elementos, assim temos a Família da Rua, a Família do Ferro, a Família da Caça, a Família da Planta, a Família da Terra (da Palha), a Família da Atmosfera (do Tempo), a Família da Cobra, a Família do Raio, a Família do Vento, a Família das Águas Doces, a Família do Mar, a Família da Lama, a Família do Branco. Ou seja, são laços de parentescos metafísicos, que impulsionam o indivíduo ao sentimento de pertencimento maior, do que apenas o ser de uma nação, raiz ou casa. Mas é um pertencimento transversal. 


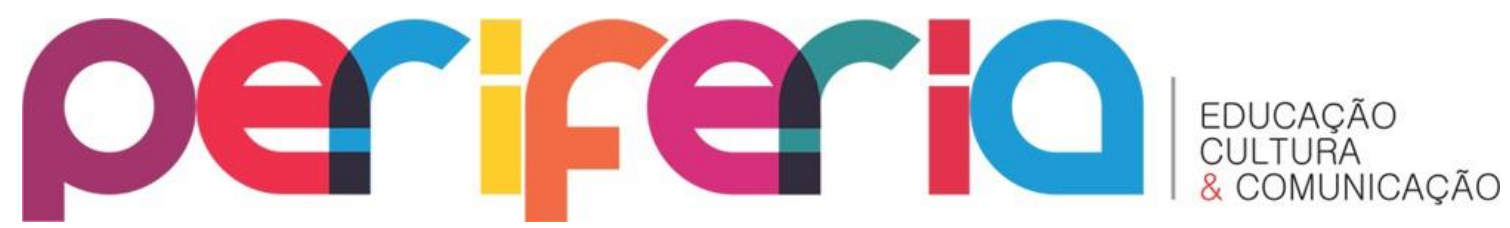

Outro ponto importante a destacar é sobre as contribuições indígenas aos cultos do Candomblé, pouco falado. Contudo, pode-se supor que foram de extrema importância, pois ao chegar no Brasil, os negros não tinham conhecimento da flora local e onde achar algumas ervas que hoje são utiliza das nos ritos.

Suponho que em momentos de trocas entre índios e negros, esses últimos narravam ritos onde usavam uma planta $\mathrm{X}$; o índio ao associar com sua própria pratica, apresentavam a planta Y que tinha a mesma função da planta X. Logo os negros usavam essa planta $\mathrm{Y}$ para substituir a que usavam em Africa, herdando igualmente uma ancestralidade indígena.

Esse cuidar com a ancestralidade perpassou barreiras linguisticas e praticas culturais e construiu um país mítico, onde o centro de suas ações culturais esta o culto aos ancestrais para permitir a expressão da alteridades dos individus. Assim, o Candomblé é uma recriação nascida de trocas culturais entre os povos africanos de tribos próximas, distantes e também de índios na produção de um terreiro potente em permitir elevar o corpo dos indivíduos na comunicação com o invisível, com os ancestrais.

\section{Intolerância um problema da segunda diaspora}

Apesar de toda riqueza cultural recriada pelo povo africano em solo brasileiro. Essa comunidade tem sofrido inúmeros ataques de intolerância. Ou o que chamamos também de ataques fundamentalistas. Esses ataques são consequência de uma segunda diaspora: a dispersão do povo de terreiro em direção a religiões fundamentalistas.

Acredito ser de extrema necessidade compreender o perigo por trás dessa segunda diáspora. Como resposta da resistência a intolerância e imposição da condição de escravos, os afros-brasileiros se encontraram em praticas lúdicas (profanas e sagradas), onde pudessem expressar as alteridades conduzindo as subjetividades à potência divina pelo transe e a brincadeira pelo carnaval. 


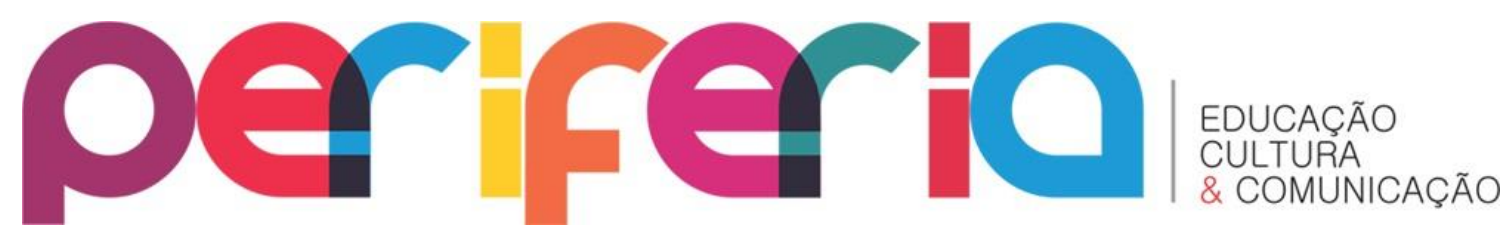

Desta maneira, chamou à atenção da academia que passou a tornar o Candomblé objeto de suas pesquisas. Contudo, o olhar eurocêntico dos pesquisadores sobre o Candomblé contribuiu para o que eu chamo de diáspora ou evasão do povo de santo.

A busca de pureza nos ritos é consequência de um olhar estranho, subjugando grupos importantes na formação dos cultos do Candomblé. Por exemplo : a afirmação da superioridade de ritos dos Yorubás sob outros povos. Alguns equívocos e negligências na interpretação das informações contribuíram na manutenção desse status quo. Roger Bastide narra um ritual de axexê de nação Angola, contudo, mesmo que no titulo de seu artigo ele nomeie a nação que lhe serve de observação, ele torna a reforçar uma superioridade dos Yorubas.

Retorno a uma problemática levantada por Stefania Capone, na qual ela aponta para o fato da concentração das pesquisas dedicadas ao Candomblé, terem se concentradoprioritariamente em três casa irmãs de nação Ketu. São elas: Casa Branca do Engenho Velho, Gantois et Opo Afonja. (CAPONE,1999, p. 16)

Em primeiro lugar é necessário considerar o Terreiro Casa Branca do Engenho Velho; como o primeiro terreiro institucionalizado. Sobretudo pelo fato das trocas, modificações e re-apropriações presentes nos terreiros de Candomblé, em comparação com os cultos encontrados na África, levaram tempos para se estruturarem. Logo, pensar na história do Candomblé apenas à partir desse terreiro é como pensar à história das Américas à partir da chegada dos europeus.

Em segundo lugar é necessário lembrar que, para cada história existe uma préhistória, muitas vezes grafada em objetos, gestos, danças e na memória dos praticantes e não pela escrita. Essa pré-história que deu os elementos necessários para a história ser contada.

Em terceiro lugar a pratica da oralidade é sustentada por lembranças guardadas na memória, mas também é marcada por esquecimentos. Assim, alguns pontos ressaltados por uns são esquecidos ou pouco valorizados por outros.

Capone atenta ainda que existem provas da existência de outros terreiro tão antigos quanto o Engenho Velho e por consequência os outros dois, dando assim um 


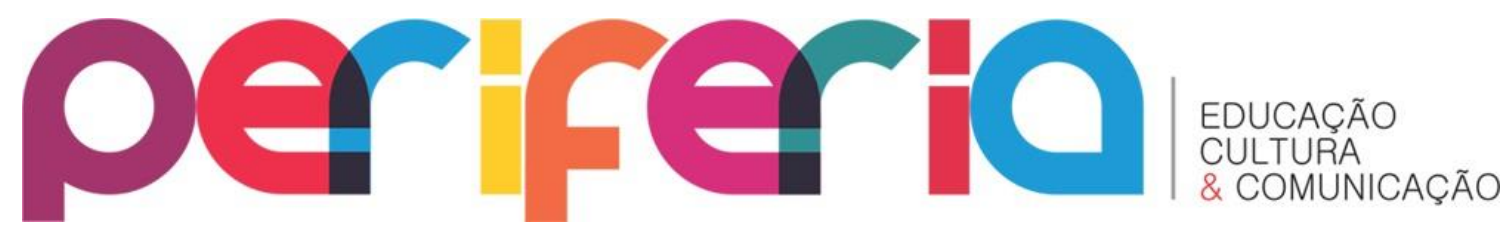

privilégio para esses supracitados. (CAPONE, 1999, p. 17) Um fator que talvez tenha influenciado seja a dificuldade de acesso aos ritos pelos outros terreiros e facilitados por esses três terreiros. Acontece que a continuidade das pesquisas sobre o Candomblé partem dessa história contada, desconsiderando a pré-história, ou seja, as contribuições e trocas com todos os povos de outras nações.

Agrava-se a esse fato as buscas do fotografo etnográfico e depois adepto do Opo Afonja, Pierre Verger. Esse buscou em Africa às praticas às divindades (nagôs) cultuadas no Brasil. Se colocando na posição de "mensageiro de dois mundos", Verger trouxesse consigo "elementos importantes" para outorgar um modelo de tradição valido para os outros cultos. (CAPONE, p. 19-20). Reforçando com isso um preconceito de pureza de uma nação frente as outras. Ou seja, que a tradição Ketu continha um estoque original de símbolos que a permitia dar continuidade para os cultos realizados em África.

Isso contribuiu para um silenciar de tambores. Casas de Candomblé que não nasceram desse tronco da Casa Branca do Engenho Velho, ou casas de outras nações como Angola ou Jeje e principalmente Ijexás, Xamba, Efon, (que foram praticamente engolidas pela nação de Ketu), tiveram os adeptos migrando dessas nações para pertencerem à "pratica mais pura". Importante frisar que à Nação Ijexá, Nação Xamba, Nação Efon quase não se ouve falar. As nações Jeje e Angola, apesar da evasão conseguiram resistir em numéros reduzidos.

O pensamento ocidental de pureza e busca por uma identidade conduziram a um processo de re-africanização, ao ponto de que hoje em dia, algumas pessoas estão suprimindo o termo "afro-brasileiro", usando "religiões de matriz africana", para indicar graficamente o pertencimento a uma pureza.

Em algumas pesquisas acadêmicas, pessoas do Candomblé passaram a ganhar voz, tornando-se sujeitos de suas pesquisas mais do que objetos, embora trazendo grande contribuições, ainda estão contaminadas por esse pensamento - essa busca de pureza e identidade. Sobretudo pesquisas realizadas por praticantes do Candomblé 


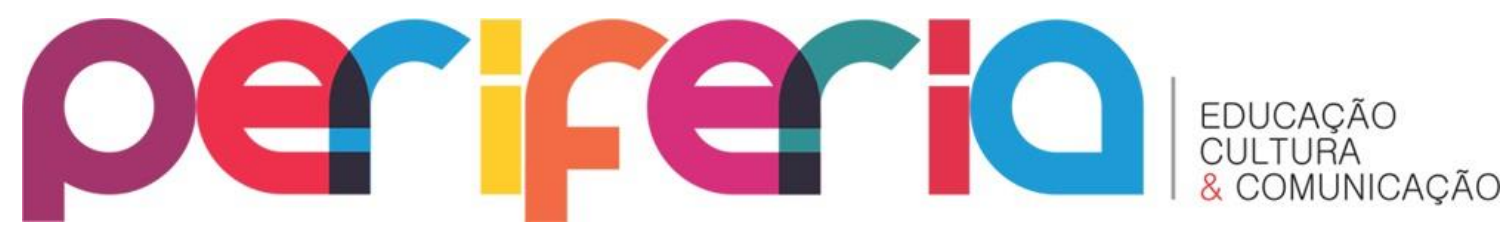

Angola, cuja proposta é mostrar o quão rico são os cultos aos Jinkisi, de onde vem parte de sua ritualística.

Contudo é importante lembrar sempre que o Candomblé é uma recriação brasileira dos rituais guardados nas memórias corporais que sofreram modificações ao se confrontarem com a realidade e praticas ja existentes no Brasil. Ou seja, essas trocas ocorridas que resultaram no Candomblé, não podem ser tratadas como apenas uma troca cultural de povo que utilizava objetos de pedras e aprendeu a usar objetos de ferro. Não, essas trocas têm um aspecto invisível de heranças, onde se aprende também do que não é visto. E tudo para contribuir na expressão do visível.

Uma prova é que apesar das diferenças de nomenclaturas, cantigas e danças, as comidas ritualisticamente são as mesmas. O milho e por consequência a pipoca são originários da América Central, desta maneira o uso desses alimentos na ritualistica do Candomblé, já demonstra uma mestiçagem, uma "impureza".

Os alimentos em todas as nações servem como veículo para que as forças invisíveis possam agir no campo de visível. Ou seja, é através do alimento que a força ancestral e elementares das divindades poderão interferir no corpo fisico trazendo Ngnzo - Axé.

Logo, o Candomblé é o resultado desse complexo processos de trocas entre povos, elaborando assim uma linguagem e uma etiqueta comum. E o que chamamos de nação, eu proponho pensar como sotaques. Em francês usa-se o termo "accent" que significa o nosso sotaque. Gosto desse termo por dar uma noção de sublinhar uma parte de algo.

Acentuar é produzir musicalidade diferentes para a mesma escritura. Assim, cada nação, é musicalidade gestual acentuadas para melhor conduzir a expressão da alteridade do adepto.

Embora o Brasil seja composto prioritariamente por povo não ocidentais (indígenas e negros) o pensamento hegemônico ainda é o ocidental, vindo pelo modelo de ensino eurocentrado, onde as informações contidas nos livros têm mais valor do que a oralidade. Assim, as pesquisas acadêmicas passaram a ter muito peso nos cultos. 


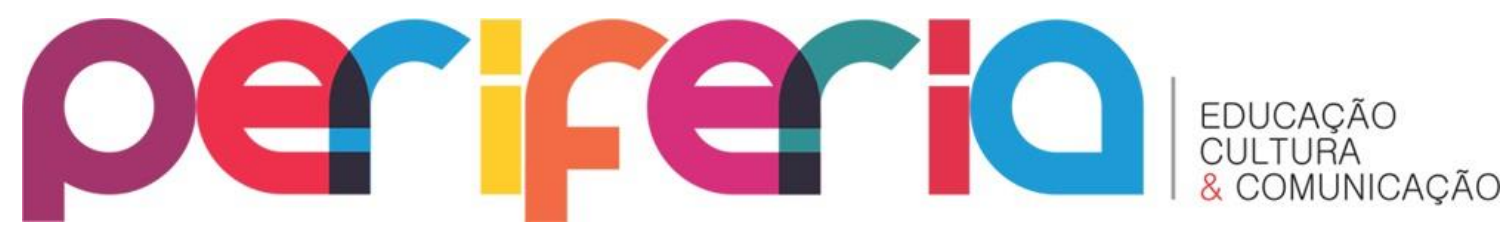

Algumas dessas serviram também como instrumento de poder para algumas pessoas do terreiro. Lembrando do velho ditado: “conhecimento é poder”! E aplicado a esse caso, ter conhecimento ou reconhecimento acadêmico é ter poder.

Algumas pesquisas passaram a formar quase "cartilhas", onde as "casas tradicionais" impunham suas maneiras de cultuar os ancestrais, logo, seu candomblé. Ou pela busca de pureza, onde alguns praticantes e casas têm modificado mesmo a maneira de falar, buscando uma "língua mais correta", mais adequada com a gramática africana contemporânea. Gramática essa formada à partir da colonização dos europeus na África. Isso acontece sobretudo no Candomblé Angola, onde as pessoas estão se especializando no Kikongo, Kibundo e Umbundo, como "línguas oficiais" do Candomblé Angola.

Ora, como tornar uma ou três línguas como oficiais, quando sabemos que no territórios como Angola, possuíam pelo menos 78 línguas diferentes? Mas o que é mais grave para mim são frases como as que li numa discussão em um grupo no Facebook sobre o Candomblé, onde uma integrante, Mametu fala.

Eu, como iniciada e estudiosa do Candomblé digo: esta moda de usar o pano na cabeça nada tem a ver com o culto, seja a nação que for. Discordo de modo veemente à utilização e para mim apenas designa Babás que ou desejam aparecer ou mesmo identificar a sua sexualidade. Ontem, em. Uma conversa com uma grande irmã e sacerdotisa eu explanei: não tenho paciência ou mesmo abertura para certas coisas que tenho observado em nome do conforto pessoal: homens de turbante e mulheres de abada. O grande problema foca no querer provar que o Candomble é tão amplo, seja Gégé, Angola, Ketu ou Ẹfọ̀n, que permite tais situações. Òrìsà pode ter me apontado. Mas a realidade mostra que, Dificilmente eu aceitaria em uma casa tais comportamentos ${ }^{7} 8$

\footnotetext{
${ }^{7}$ https://www.facebook.com/photo.php?fbid=1481813101903843\&set=gm.1880707561944634\&type=3\& theater\&ifg=1

${ }^{8}$ Copiei e colei a mensagem como foi colocada na discussão numa comunidade no facebook, contudo não vou mencionar nomes ou dijinas, para resguardar a pessoa. Principalmente porque meu intuito é usar o exemplo para uma reflexão maior do que a discussão levantada. Grifos do autor
} 


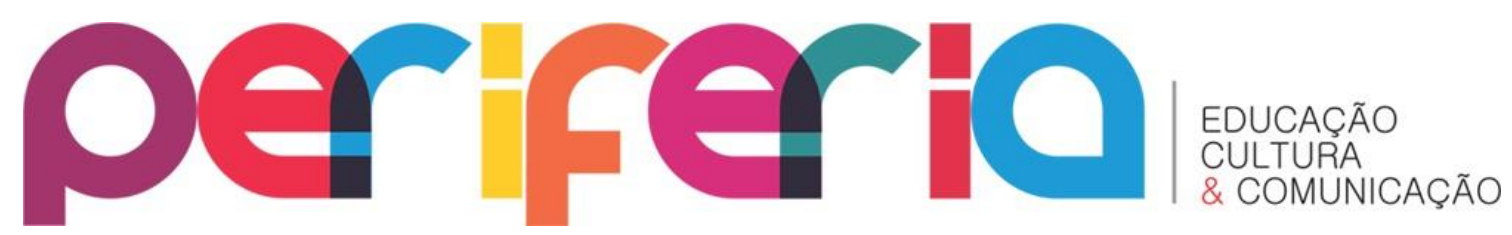

Tudo à partir de uma publicação de um Tata que colocou: "Na nação Kongo/Angola, exceto em preceitos, pano na cabeça do ser humano do sexo masculino é apenas enfeite para despertar a atenção de leigos".

Ora esse tipo de argumento tão afirmativo fere e rebaixa a alteridade do outro, o aprendizado do outro. Descredibiliza o antepassado do outro. Isso gera o caminho da evasão, da diáspora do povo de terreiro para um reagrupamento junto a práticas intolerantes, fundamentalistas.

Proponho fazer o exercício de pensar como alguém que lê ou escuta algo dessa natureza: "se o que vale é o que está escrito nos livros e se meus antepassados estavam errados, o melhor a fazer é me converter para uma religião onde desde o inicio há uma obediência a um livro, desde sua formação, com dogmas já mencionados”.

Assim ocorre a diáspora (dispersão) do povo de terreiro em direção as praticas fundamentalistas, ou seja, eles se utilizam de fundamentos religiosos como resposta para descredibiliza as práticas do outro como eles mesmo já sofreram.

Certamente esse pensamento já passou gerações e se perderam, onde o que esses fundamentalistas aprenderam com seus ancestrais é a resposta agressiva contra a prática que possibilita a alteridade do outro.

Pode-se verificar que esses grupos neo-pentecostais se utilizam de elementos da ritualística do Candomblé como ferramentas na construção dos próprios cultos. Vale ainda ressaltar que, esses adeptos não estão preocupados com o que o outro faz na sua igreja, pois existe uma certeza que esses estão no "caminho certo". Já que cada igreja tem se tornado um "quilombo cristianizado" onde eles têm encontrado a possibilidade de se expressar fundada num "livro sagrado".

Desta maneira é fundamental para nós, pesquisadores-praticantes do Candomblé, buscarmos uma reflexão do posicionamento de nossas colocações diante do povo de terreiro. Que o resultado de nossas pesquisas vem do olhar da nossa alteridade diante da 


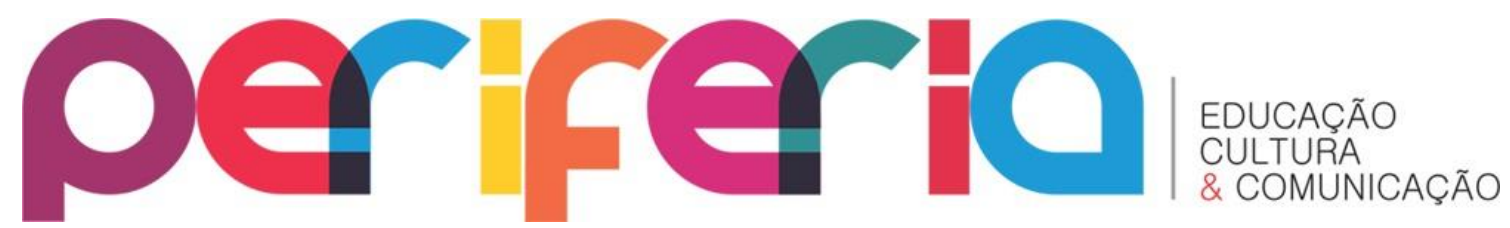

comunidade que está em diálogo com os ancestrais, mas também com o contemporâneo e com os decendentes.

Faz-se urgente um posicionamento ético do pesquisador diante da comunidades do Candomblé. A nossa função de pesquisadores-praticantes, é de valer de nossas pesquisas para garantir a expressão da alteridade do outro, lembrando que uma parte dos praticantes do Candomblé é formada por pessoas simples, de baixa escolaridade, onde a hierarquia da "pessoas estudada" tem grande peso. As pesquisas sobre o Candomblé não devem aprisionar, mas potencializar a exploração das encruzilhadas.

Faz-se necessário ainda um pensamento critico diante da história, verificando assim os benefícios que essa história trouxe à "casas tradicionais" e o que gerou algumas migrações. Continuo, assim, com a fala da mesma Mametu:

\begin{abstract}
Em nenhum momento eu tentei impor a minha presença ou vontade à casa alheia. Muito pelo contrário. E os grandes nomes que usaram os benditos panos na cabeça, PAGARAM para ingressar em casa tradicional que nunca os aceitou... Se nós, İyá, Babás, Tatas, Máamas, estamos tão errados em questionar adereços femininos em homens e vice e versa, porque será que os tais cabecoes midiaticos foram pedir arrego nesta casa Matriz? ${ }^{9}$
\end{abstract}

Ora, à partir dessa fala vemos que as "casas tradicionais", matrizes se beneficiaram com recursos financeiros para "aceitarem" quem ela nunca aceitou"? Mas ai temos um problema ético, pois a casa matriz acaba aceitando, desde que "paguem" por isso? E vemos que essas mesmas casa têm mais força do que os "cabeçoes midiáticos", que necessitaram da tutela dessas "casas tradicionais puras" para dar seguimento a sua prática.

Ou seja, afirmações e questionamentos que se tornam um terreno perigoso para se plantar "certezas" que desvalorizem as expressões de alteridade do outro, pois o fruto

https://www.facebook.com/photo.php?fbid=1481813101903843\&set=gm. $1880707561944634 \&$ type $=3 \& \mathrm{t}$ heater\&ifg $=1$

Revista Periferia, v.10, n.1, p. 213 - 228, Jan./Jun. 2018 


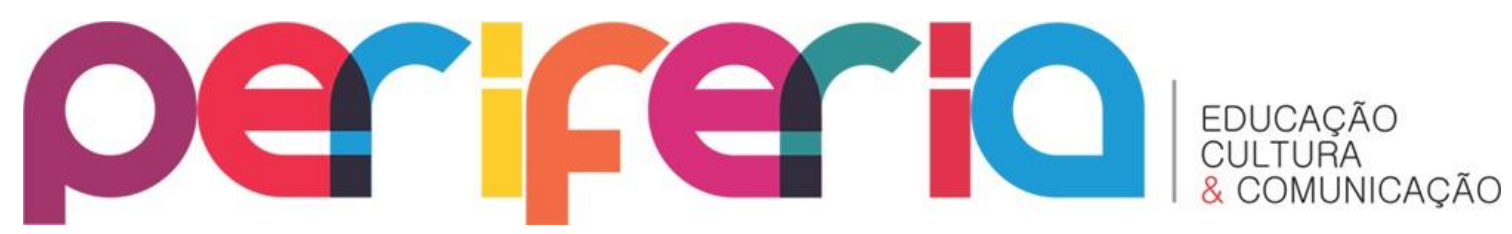

colhido pode ser a intolerância religiosa em resposta a essa intolerância interna. Ressalto porém, que a intenção desse artigo não é de questionar as "casas tradicionais", mas pontuar a necessidade de relativizar conclusões baseadas nas informações geradas pela academia.

Vale lembrar da mítica frase do Candomblé: "que cada um mexe a sua panela como sabe". Essa frase também pode ser lida como "cada um mexe sua panela como aprendeu" - com as respostas à necessidade daquela tribo-terreiro-raiz-nação. Se cada um procurar respeitar os fundamentos-ingredientes de suas panelas, o Candomblé resistirá com um grande banquete ao Rei, onde Nsumbo-Obaluaie-Azaoani compartilha com todos a diversidade de alimentos a ele ofertada. A intolerância externa perderá força quando a tolerância interna ganhar força.

\section{Considerações Finais}

Encruzilhada é o lugar de morada de Aluvaia, de Exu, de Legbara; é o cruzamento de caminhos. Ao mesmo tempo que aponta para varias direções, é também o ponto de chegada de diversos caminhos.

Pode-se afirmar que o Candomblé é uma encruzilhada de etnias, onde cada tribo aprendeu como cultivar o ancestral do outro, formando clãs metafísicos que se religam em elementares. As divindades são as mesmas, as ancestralidades são maneiras de cultivar e cuidar dessas energias.

Uma encruzilhada que aponta para várias direções, papéis, funções que o indivíduo executa para expressar sua alteridade, saindo assim da sua sub-condição da realidade social na qual pertence.

Enquanto Terreiro de resistência que acolhe, cuida e torna possível a expressão de alteridade, o Candomblé criou esses clãs metafísicos que quebram fronteiras de nações. São clãs-encruzilhadas por onde perpassam nações, raízes, axés, tribos.

O Candomblé e como uma boa encruzilhada, onde não se apresenta apenas um caminho, mas no mínimo sete (frente - trás -lado esquerdo - lado direito - encima - 


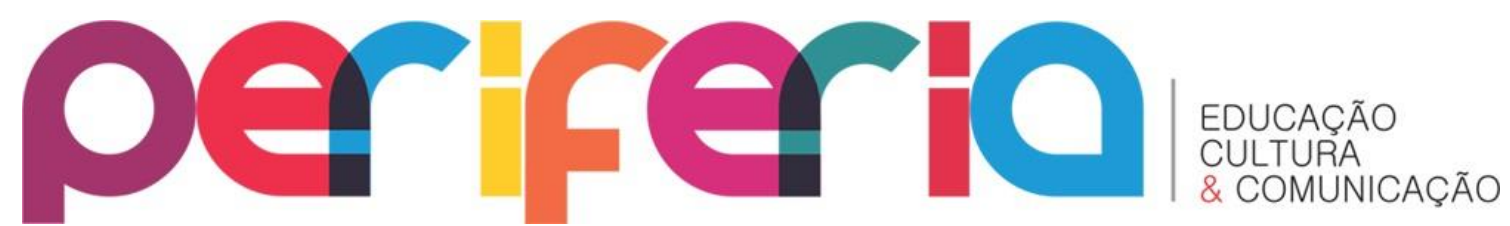

embaixo - interior). Cada caminho de uma encruzilhada pode conduzir a outra encruzilhada e a outra...

As modificações ocorridas sãos respostas as perguntas e necessidades de cada tribo-terreiro-raiz-nação-encruzilhada. Deve-se supor que essas modificações ocorrem em dialogo com a ancestralidade de cada terreiro. E que devem servir como normativas para os praticantes daquela tribo.

O mais importante é compreender que o Candomblé é a resposta que os afrobrasileiros encontraram que pode ser equiparado ao princípio de africanidade dos povos africanos : que quer dizer a unidade na diferença através do culto aos ancestrais.

Assim o uso de fundamentos de um terreiro-raiz-nação para rebaixar ou discriminar a alteridade do outro é se valer de "fundamentalismo" que impõe uma crença sobre a do outro. Esse tipo de ação contribui para a diáspora (dispersão - evasão) do povo de terreiro, tendo uma onda de intolerância como resposta.

Enfim, : mais que uma religião, o Candomblé é um TERREIRO de expressão cultural, onde os ritmos dos tambores fazem mover os corpos, as roupas, os paramentos, numa estética que religa o tempo ancestral ao tempo contemporâneo na expressão de alteridade.

Referências :

ADOLFO, Sérgio Paulo. Nkisi Tata Dia Nguzu. Estudos sobre o candomblé Congo-Angola. Londrina : Eduel. Londrina, 2010.

AMARAL, Rita. Xirê! O modo de crer e de viver no Candomblé. Rio de Janeiro : EDUC \& Pallas Editora, 2002.

CAPONE, Stefania. La quête de l'Afrique dans le candomblé : pouvoir et tradition au Brésil. Paris : Édition KARTHALA, 1999.

COSSARD, Gisèle Omindarewá. Awô, Mistérios dos Orixas. $2^{\circ}$ ed. Rio de Janeiro :Pallas.R 2011.

KOLEAS, Bernard Bakana. Les épreuves initiatiques chez les Bantus. Paris : Menaibuc, 2007.

LAPLANTINE, François. e NOUSS, Alexis. Le Métissage. France S/L : DOMINOS Flammario, 1997.

Documentário

Devoção. Direção : Sérgio Sanz, Produção : J. Sanz. Rio de Janeiro (BR), 2008, 1 DVD 